\title{
Representação social acerca da assistência de enfermagem prestada a mulheres grávidas usuárias de crack na Maternidade e Centro Obstétrico
}

\author{
Jeferson Ventura \\ Enfermeiro, Doutor em Enfermagem pelo PPGEnf-FURG. Membro do Grupo de Estudo e Pesquisa em \\ Enfermagem e Saúde da Criança e do Adolescente (GEPESCA) \\ 凶enf.jefersonv@gmail.com \\ Giovana Calcagno Gomes \\ Enfermeira. Doutora em Enfermagem pela Universidade Federal de Santa Catarina (UFSC). Docente FURG. \\ Líder do Grupo de Estudo e Pesquisa em Enfermagem e Saúde da Criança e do Adolescente (GEPESCA) \\ $\triangle$ giovanacalcagno@furg.br \\ Juliane Scarton \\ Enfermeira. Doutora em Enfermagem pela Universidade Federal do Rio Grande (FURG) Membro do Grupo de \\ Estudo e Pesquisa: Gerenciamento Ecossistêmico em Enfermagem/Saúde (GEES/CNPq) \\ 凶juliscarton10@hotmail.com \\ Deisa Salyse dos Reis Cabral Semedo \\ Enfermeira. Doutora em Enfermagem pela FURG. Docente da Universidade de Cabo Verde (UNIVC)- África \\ $\bowtie$ deisasemedo@gmail.com \\ Rosiane Filipin Rangel \\ Enfermeira. Doutora em Enfermagem pela FURG. Docente da Universidade Franciscana - UFN. Membro do \\ GEES/CNPq \\ \rosianerangel@yahoo.com.br \\ Maria Helena Gehlen \\ Enfermeira. Doutora em Gerontologia pela PUC-POA. Docente da Universidade Franciscana - UFN. Membro do \\ GEPEFES/CNPq \\ $\triangle$ gehlenmh@gmail.com
}

Recebido em 6 de abril de 2020

Aceito em 7 de agosto de 2021

\section{Resumo:}

Este estudo objetiva-se conhecer as representações sociais de enfermeiras que atuam em Maternidade e Centro Obstétrico acerca da assistência de enfermagem prestada à mulher grávida usuária de crack nos setores. Trata-se de uma pesquisa qualitativa. Usou como referencial teórico a Teoria das Representações Sociais. Participaram 14 enfermeiras que atuavam na maternidade e centro obstétrico. Os dados foram coletados em 2018 por entrevistas semiestruturadas e analisados pela técnica do Discurso do Sujeito Coletivo. Os resultados revelaram que a preocupação da equipe é com o bebê que irá nascer. Muitas mulheres são tratadas com preconceito, tanto pelos médicos como enfermeiros. As crenças, valores dos profissionais influenciam na forma como são tratadas. As mulheres usuárias de crack são marginalizadas, e por vezes não possuem as mesmas chances que as outras pessoas. Conclui-se que é necessária a capacitação dos profissionais de saúde que atuam na assistência a essas mulheres, afim de qualificar o cuidado a estas mulheres, para minimizar o estigma que envolve a temática do uso de crack e do ser mulher gestante.

Palavras-chave: Usuária de drogas, Gravidez, Crack, Pessoal de Saúde, Enfermagem. 


\title{
Social representation about the assistance provided to pregnant women who are crack users at the Maternity and Obstetric Center
}

\begin{abstract}
:
This study objective to know the social representations of nurses who work in Maternity and Obstetric Center about nursing care provided to pregnant women who are crack users in the sectors. It is a qualitative research. He used the Theory of Social Representations as a theoretical framework. 14 nurses who worked in the maternity ward and obstetric center participated. Data were collected in 2018 by semi-structured interviews and analyzed using the Collective Subject Discourse technique. The results revealed that the team's concern is with the baby that will be born. Many women are treated with prejudice, both by doctors and nurses. The beliefs, values of professionals influence the way they are treated. Women who use crack are marginalized, and sometimes do not have the same chances as other people. It is concluded that it is necessary to train health professionals who work in assisting these women, in order to qualify the care for these women, in order to minimize the stigma surrounding the theme of crack use and being a pregnant woman.
\end{abstract}

Keywords: Drug user, Pregnancy, Crack, Health Personnel, Nursing.

\section{Representación social sobre cómo las mujeres que usan crack son recibidas en la sala de maternidad y en el centro obstétrico}

\section{Resumen:}

Este estudio tiene como objetivo conocer las representaciones sociales de las enfermeras que laboran en el Centro de Maternidad y Obstetricia sobre la atención de enfermería brindada a las embarazadas usuarias de crack en los sectores. Es una investigación cualitativa. Usó la Teoría de las Representaciones Sociales como marco teórico. Participaron 14 enfermeras que laboraban en maternidad y centro obstétrico. Los datos fueron recolectados en 2018 mediante entrevistas semiestructuradas y analizados mediante la técnica del Discurso Colectivo del Sujeto. Los resultados revelaron que la preocupación del equipo es el bebé que nacerá. Muchas mujeres son tratadas con prejuicios, tanto por médicos como por enfermeras. Las creencias, los valores de los profesionales influyen en la forma en que son tratados. Las mujeres que consumen crack son marginadas y, a veces, no tienen las mismas oportunidades que otras personas. Se concluye que es necesario capacitar a los profesionales de la salud que trabajan en la atención a estas mujeres, a fin de calificar la atención a estas mujeres, con el fin de minimizar el estigma que rodea el tema del uso de crack y la gestación.

Palabras clave: Consumidor de drogas, Embarazo, Crack, Personal de salud, Enfermería.

\section{INTRODUÇÃO}

A equipe de saúde tem um importante papel no cuidado à gestante usuária de crack, pois é no ambiente de saúde que a mulher vai ser acolhida, receber apoio e cuidados necessários para enfrentar a problemática do consumo de drogas. Pois se esta mulher for bem tratada, receber apoio e cuidado ela terá mais chance de conseguir se recuperar e consequentemente fortalecer os vínculos com a criança após o parto.

Mulheres usuárias de crack têm dificuldades em procurar os serviços de saúde, sendo um dos motivos o fato de sentirem-se estigmatizadas e sofrerem preconceito nos ambientes 
de saúde. O estigma social associado ao uso do crack é uma forte barreira para as mulheres que buscam tratamento, visto que o uso da droga vai contra o comportamento feminino imposto e esperado socialmente (CAMARGO et al., 2018)

Muitas mulheres usuárias de crack trocam a droga pelo sexo, moram na rua e apresentam vulnerabilidade social, sendo excluídas do convívio social (BOSKA et al., 2017). Tal realidade pode despertar-lhes sentimentos de marginalização que as afastam dos serviços de saúde (SILVA, PEREIRA, PENNA, 2018).

Um dos motivos que prejudicam de modo direto o cuidado às mulheres usuárias de crack é a visão de que são perigosas, imorais e responsáveis pela sua condição. Parece haver entre os profissionais da saúde a percepção de que o uso de drogas não é um problema de saúde, mas, uma falha de caráter, fazendo com que seja atribuído exclusivamente a esta população a responsabilidade pelo uso da droga, dificultando seu acolhimento e acesso nos serviços de saúde (OLIVEIRA, 2020)

Outro fator que pode interferir diretamente nas perspectivas de cuidado às mulheres usuárias de crack é a burocracia exigida nos serviços de saúde como, por exemplo, necessidade de comprovação de identidade e endereço, o que muitas vezes as mesmas não têm condições de atender. Verifica-se a necessidade dos serviços de saúde se prepararem para dispensar um atendimento específico a estas mulheres, pois se encontram em situação de vulnerabilidade social. Por estas razões é necessário que as equipes sejam melhores capacitadas e treinadas, para dispensar um melhor aconselhamento e apoio psicológico, permitindo assim que o ambiente dos serviços de saúde se torne mais humanizado e acolhedor (MACIEL, et al, 2020).

As gestantes usuárias de crack necessitam de apoio social com um olhar diferenciado e compreensivo, para que consigam enfrentar o medo e a inabilidade frente à problemática, sendo que os profissionais precisam dar-lhes suporte. Considera-se que a Maternidade é um setor do hospital provido de recursos de pessoal, material e financeiro para atender as demandas referentes à gravidez, e que nesta situação os profissionais são responsáveis, frente a essas mulheres, de promoverem subsídios favoráveis à sua saúde mental da gestante e de assistência ao recém-nascido (VENTURA, et al, 2019). 
Apesar de não existirem dados epidemiológicos fidedignos no Brasil, acerca dos números de gestantes usuárias de crack, as maternidades e centros obstétricos, assim como os profissionais que lá atuam necessitam estar preparados para receber e atender esta parcela da população que muitas vezes ficam a margem da sociedade, para que assim estejam aptos a conduzirem o trabalho de parto destas mulheres e o acompanhamento do puerpério imediato (XAVIER et al.., 2018).

Ainda segundo Xavier et al, (2018), o profissional enfermeiro enquanto educador, precisa passar orientações acerca dos cuidados com a sua saúde, bem como a saúde do bebê, observando os possíveis fatores de riscos sociais, fornecendo-lhes os devidos encaminhamentos de modo que estas mulheres se sintam acolhidas dentro dos ambientes de saúde, para que possam conseguir superar as dificuldades relacionadas ao uso de crack, criando habilidades e competências para o cuidado do recém-nascido.

Assim, este estudo justifica-se pela necessidade de aprofundar conhecimentos acerca da forma como as mulheres usuárias de crack são assistidas na Maternidade e Centro Obstétrico. Com base no exposto, tem-se como questão norteadora: Quais as representações sociais de enfermeiras que atuam em maternidade e centro obstétrico acerca da assistência prestada à mulher grávida usuária de crack no setor? Por estas razões este estudo tem como objetivo conhecer as representações sociais de enfermeiras que atuam em Maternidade e Centro Obstétrico acerca da assistência prestada a mulheres grávidas usuárias de crack nos setores.

\section{MÉTODO}

Trata-se de uma pesquisa descritiva, exploratória com abordagem qualitativa (MINAYO, 2014). Teve como referencial teórico a Teoria das Representações Sociais de Sergei Moscovici. Participaram deste estudo, 14 profissionais enfermeiras que atuavam na maternidade e centro obstétrico de um hospital do sul do Brasil. Foi utilizado como critério de inclusão atuar no setor há pelo menos quatro meses, pelo fato de conhecer o perfil de internação na unidade e exclusão estar de férias ou licença saúde no período da coleta dos dados. 
Os dados foram coletados no segundo semestre de 2018, por meio de entrevistas semiestruturadas, pelo pesquisador principal. As quais foram gravadas e após transcritas na integra. As enfermeiras foram questionadas acerca da frequência de atendimento de mulheres usuárias de crack; diferenças no comportamento dessas mulheres em relação às não usuárias; Como se dá o recebimento dessas mulheres no setor; Existem diferenças no trabalho de parto das mulheres usuárias de crack e aquelas que não fazem uso; Como é o cuidado que as mulheres usuárias de crack prestam ao recém-nascido após o parto; Como é o cuidado familiar a essas mulheres no setor; Que necessidades de cuidados essas mulheres necessitam receber no setor; Qual a dificuldade para prestar-lhes assistência as mulheres usuárias de crack; Como é assistência de enfermagem prestada a essas mulheres no setor.

Os dados foram submetidos à análise pelo Discurso do Sujeito Coletivo. Esse consiste na organização e tabulação de dados qualitativos de natureza verbal, obtidos de depoimentos, artigos de jornal, matérias de revistas semanais, papers, extraindo de cada um as ideias centrais e/ou ancoragens e suas correspondentes expressões-chave. Nesta técnica, por meio dos depoimentos, se busca reconstruir, com fragmentos de discursos individuais, discursossíntese que expressem uma forma de pensar ou representação social sobre um fenômeno (LEFÈVRE E LEFÈVRE, 2012).

O estudo respeitou a Resolução 466/12 referente à realização de Pesquisas com Seres Humanos (BRASIL, 2012). Foi iniciado somente após a aprovação do projeto de pesquisa pelo Comitê de Ética em Pesquisa com Seres Humanos (CEP) da Universidade Federal de Rio Grande (FURG), sob o número 113/2018 e CAAE 90845618.3.0000.5324. As participantes assinaram o Termo de Consentimento Livre e Esclarecido em duas vias e para garantir o anonimato foram identificadas pela letra E seguida do número da entrevista.

\section{RESULTADOS}

Participaram do estudo 14 enfermeiras. Destas, seis atuam no centro obstétrico e oito na maternidade. As idades variam entre 28 e 48 anos, com média de idade 38,7 anos. 0 tempo de profissão das participantes variou entre um e 18 anos, com média de 11,8 anos de atuação na enfermagem. Desenvolvem atividades na maternidade e centro obstétrico entre quatro meses e 16 anos, com média de atuação nestes setores de 4,1 anos. 
A análise dos dados deu origem a oito Ideias Centrais:

Ideia central 1: As mulheres usuárias de crack são recebidas da mesma forma que as que não fazem o uso do crack.

DSC: Eu não vejo diferenciação. Geralmente dou atendimento igual para todas as usuárias. Elas são recebidas da mesma maneira que as outras mulheres, sem distinção. Não há uma diferenciação no acolhimento por serem usuárias de crack. Se o Centro Obstétrico chama eu recebo, se tiver que fazer algum protocolo, é feito, tudo como qualquer outra internação. 0 tratamento é o mesmo, pelo menos da parte da enfermagem. Tento tratar elas da mesma forma que trato as outras, com respeito, com carinho, com atenção (E1, E5, E6, E7, E8, E9, E10, E11, E12, E13 E14).

Ideia central 2: A preocupação por parte da equipe é com o bebê que irá nascer.

DSC: As pessoas tendem a ter uma atenção maior em relação ao bebê, como vai nascer e o que vai acontecer depois com essa criança. Tenho um cuidado maior com o bebê, às vezes levo ele até o posto e dou mamadeira, troco fralda, dou banho, faço todo o cuidado que tem que ser feito. Quando elas estão bem sonolentas eu sempre digo que posso pegar o bebezinho e deixar no Posto de Enfermagem, para que ela possa descansar. Tenho que ficar vigiando, uma vez peguei o bebê e levei para o posto de enfermagem, a mãe não queria nem ver a criança. Como sou mãe, já fica um clima diferente, porque uma usuária trata bem, mas se é uma que maltrata o bebê já fico assim, me coloco no lugar do bebezinho. Eu cuido se ela não vai ser agressiva com o bebê e se não vai dormir em cima do bebê. [...]. Elas aguentam mais a dor do trabalho de parto, eu não sei se é porque elas estão mais "alienadas", mas elas não conseguem amamentar, tem que esperar o tempo de se "limpar". Percebo que elas querem vivenciar aquele momento, mas elas não têm condições psicológicas de cuidar de uma criança. Elas já vêm do Centro Obstétrico e já aviso a equipe de que aquela mãe é usuária, porque tem que ter uma atenção maior para ver se ela dá atenção ao bebê, se o leite está sendo dado nos horários, se os cuidados do RN estão sendo feitos. Tento que o bebê fique com ela, mas, a fico em cima também, com medo que aconteça alguma coisa com o bebê. Vejo alterações do bebezinho, é um bebe mais agitadinho, é um bebe que não tem aquele olhar sereno de RN, é um olhar diferente. Existe um manejo específico com o RN, que se ela tiver utilizado a droga com menos 
de 24 horas tem que esperar um tempo para iniciar a amamentação. Um bebê morreu de desnutrição e a outra criança de 2 anos tinha peso de meses. Essas situações são coisas que esse bebê pode vir a estar passando, principalmente se não tiver um acompanhamento fora do hospital. Fico preocupada e penso: "Esse aí tomara que Deus ajude e que as Conselheiras realmente façam esse acompanhamento". Não deixa de ser mais um bebê indefeso e que está sujeito a ir parar na rua, de repente, porque ela não vai ter condições. Quase todas que eu atendi, usuárias de crack, nasceram prematuros, não me lembro de nenhum eu entregar direto para a mãe, todos foram preciso levar para a NEO. As vezes é feto morto, então vejo muito feto morto, é muito triste isso. Tem pacientes que relatam que usaram e já chegam aqui em trabalho de parto prematuro ou com algum problema na gestação (E1, E3, E5, E6, E7, E8, E9, E10, E11, E13, E14).

Ideia central 3: O fluxo de atendimento das mulheres usuárias de crack no hospital e fazer uma ficha de atendimento no Pronto Socorro, encaminhar ao Centro Obstétrico e caso necessitem ou após o parto ficam internadas na maternidade.

DSC: Não tem acolhimento com classificação de risco aqui. Elas fazem a ficha de atendimento lá no Pronto Atendimento, sobem para o Centro Obstétrico e entregam a ficha, aguardam atendimento e são avaliadas pelo médico para ver se interna ou não. Se estiverem mesmo em trabalho de parto ou já ganhando vão para o leito e são atendidas. Se vai ficar internada ou algum atendimento, tento coletar algumas informações a respeito dela, se teve gestação anterior, quando é que foi, se este bebê está com ela ou se não está, as testagens rápidas. Ver se precisa entrar com algum protocolo e depois somente no momento do parto para conhecer quais são as condições que esta paciente tem. Se elas tiverem algum problema ou se elas apresentarem alguma intercorrência, elas internam antes na Maternidade, ou se não elas vão para ganhar o bebê no Centro Obstétrico e de lá elas vêm para cá. Elas são recebidas no Centro Obstétrico, ficam em trabalho de parto se der para evoluir para o parto normal faz o parto normal, caso contrário vai para cesariana (E2, E3, E5, E6, E7, E12).

Ideia central 4: Mulheres usuárias de crack ao serem recebidas no setor sofrem algum tipo de discriminação por parte de alguns profissionais. Esses fazem julgamentos, indiretas, 
comentários, críticas, deboche, deixam as mulheres sozinhas, não conversam com elas e têm algum tipo de preconceito.

DSC: Uma questão que elas enfrentam é a violência, de virem falar diretamente e das indiretas, são tipos de violência também, os comentários e as indiretas: -Está nessa vida por quê? -Não tem ninguém por você? -Todo mundo já te abandonou? Eu acho que a enfermagem consegue ver um pouquinho melhor essa paciente, mas o profissional médico parece que tem um pouco, eu não posso te dizer se é aversão, se é julgamento ou de achar que ela está daquele jeito porque simplesmente quer. Às vezes quem faz um tratamento diferenciado, para mim, discriminatório, é porque acha que a pessoa está ali porque quer. Já que tem tanto tratamento por aí e é tão fácil fazer o tratamento, então por que não faz? -Não faz porque não quer. Normalmente, mais de $90 \%$, quando passa a paciente, já passam com aquela crítica: -Chegou a fulana e é usuária, está chapada, está na cara que está drogada. Algumas deixam sozinhas, fazem o que tem que fazer e saem, não conversam, já sabem o que vai acontecer: -É que elas não estão ouvindo mesmo o que eu estou falando. Às vezes algum comentário que estão sujas, comentários preconceituosos. Tem uma pessoa mais antiga que já está há bastante tempo e que já tem um pré-conceito formado. [...]. Muitas vezes fazem comentários e nem sabem como foi o antes daquela pessoa. Na verdade, eu penso que as pessoas não sabem qual o histórico de vida e já vai logo com esse preconceito, com a visão bem fechada. Às vezes elas são mal recebidas e por conta disso são agressivas, não são colaborativas. Eu sinto que as pessoas ficam um pouco mais diferenciadas no tratamento. Mas a maioria tenta não tachar. Só por ser usuária terá um tratamento diferenciado. Quando avisam que é usuária acabo tendo um cuidado maior, seja pela questão do furto. A enfermeira do Centro Obstétrico quando faz a liberação, já comunica: -Esta paciente é usuária de crack. -Tem um marido estranho vai lá fora. Sempre que elas observam algo de diferente elas me informam. Me preparo no sentido de colocar esta paciente em uma enfermaria sozinha, se der. Isso é um medo que eu tenho, quando eu vejo estas pacientes usuárias chegando aqui, geralmente o namorado, marido, companheiro também é usuário. Então, são pessoas que tenho que ter um pouco de cuidado, procurar não deixar o posto sozinho. Percebo muito, principalmente na classe médica, acabam discriminando a mulher, dizendo que elas trazem prejuízos não para elas, mas para os filhos. Se acaba acontecendo alguma coisa elas são responsáveis, se o bebê nasceu ruim, é dito: -Está vendo foi por sua culpa que o bebê nasceu deste jeito. Lembro que quando as pessoas foram grosseiras, ela revidou com grosseria e as pessoas se afastaram. Tem algumas 
que tratam bem, outras não. Mas tem o preconceito infelizmente. Às vezes é involuntário no olhar: -Se são usuárias por que fazem um filho? -Colocam mais uma criança no mundo para sofrer. Uma foi recepcionada lá na frente e quando a técnica me chamou, ela já veio rindo e me disse: -Tem uma moça que tem dois maridos e quero saber quem vai entrar? E a médica também, no fim estava aquele deboche (E2, E4, E5, E8, E9, E10, E11, E12, E13, E14).

Ideia central 5: Mulheres que são usuárias de crack são tratadas de forma diferenciada e com preconceito pelos membros da equipe tanto médica como de enfermagem e não são bem recebidas no setor.

DSC: Posso te dizer que não é todo mundo que trata igual a paciente, não é específico só de uma classe A ou B, de médicos ou enfermeiros. Eu acho que o preconceito aqui no nosso hospital é bem grande pela parte médica, que é quem recebe elas num primeiro momento e não vejo pela enfermagem, pela equipe em si. Algumas fazem o que tem que fazer de papelada e largam e seja o que Deus quiser, na hora que tem que nascer, vai nascer e pronto, tanto da parte médica como até da enfermagem. Aqui, de uma forma geral, tento não diferenciar, mas tem algumas dessas mulheres que são muito trabalhosas (E2, E4, E5, E9).

Ideia central 6: A forma como estas mulheres são recebidas no setor depende das crenças, valores e concepções de vida de cada profissional.

DSC: A forma como estas mulheres vão ser recebidas vai depender das crenças e valores de cada profissional. A maioria consegue ver um ser humano ali atrás, que precisa de ajuda e que por mais que queira ajudar, sei que aqui vai ter um atendimento mais digno possível para ela. [...]. Eu acredito que seja por concepções que a pessoa traz durante a vida, não sei como a pessoa enxerga a sociedade. [...]. Segurança não tem e cada pessoa teve alguma história pessoal, de repente já foi assaltada, teve tentativa de assalto por uma pessoa que é usuária de crack ou de drogas. Cada um carrega muitas coisas que vão afetar aqui diretamente na assistência prestada. O ser humano é muito complicado. Cada um tem suas crenças e é claro que fala alguns termos que são pejorativos. Têm profissionais que falam mal. Isso depende de cada pessoa. Cada pessoa tem seu jeito de ser e de usar as palavras. Eu acho que depende 
muito da pessoa, não em relação à categoria profissional. Depende muito do caráter de cada um, da pessoa. Às vezes tem instrução, tem nível superior e tem uma conduta assim. Age desta forma, infelizmente (E2, E9).

Ideia central 7: Os profissionais acreditam que as mulheres usuárias de crack são marginalizadas, não possuem as mesmas chances que as outras pessoas de se recuperarem e conseguirem um trabalho.

DSC. Esse discurso ele é muito fácil explicar: -é um usuário porque ele é um marginalizado, porque é preto, porque é isso, porque é aquilo. As chances não são as mesmas. Por mais que a pessoa se reabilite, que se recupere fisicamente e emocionalmente, ela vai para o mercado de trabalho e não tem as mesmas chances do que a outra pessoa. Mas eu não sei se é infelicidade mesmo da pessoa ou se não é a incapacidade do outro ver e dar graças a Deus que está numa situação melhor. Eu tenho emprego, eu tenho uma situação boa (E2).

Ideia central 8: As pessoas que prestam a assistência às mulheres usuárias de crack são acolhedoras durante o cuidado.

DSC: Eu acho que as pessoas com quem eu tive contato sempre foram muito acolhedoras nesse sentido (do cuidado). A forma como ela é acolhida vai aparecer lá no bebê e nela. É uma caminhada longa, porque o preconceito é muito grande com elas. Então, precisam ser bem acolhidas no serviço. Mesmo com essas que são usuárias eu procuro ser acolhedora, ter uma relação bem boa, até justamente para poder chegar e prestar uma assistência e um cuidado que elas especificamente precisam (E1, E4, E8).

\section{DISCUSSÃo}

Em relação à forma como as mulheres usuárias de crack são recebidas no setor as representações sociais da equipe são de que essas são recebidas da mesma forma que as que não fazem o uso do crack, mas a preocupação maior da equipe é com o bebê que irá nascer. 
Evidenciou-se, no entanto, que sofrem discriminação e preconceito por parte de alguns profissionais. Tal prática ancora-se em crenças, valores e concepções de vida de cada profissional. Há a crença de que essas são marginalizadas, não possuem as mesmas chances que as outras pessoas de se recuperarem e conseguirem um trabalho. Apesar disso, as profissionais que prestam assistência às mulheres usuárias de crack são acolhedoras durante o cuidado.

Em um estudo realizado pela UNODC (2015), estima-se que mais de 5\% da população mundial (246 milhões de pessoas) com a idade entre 15 a 64 anos, já tenham feito o uso de algum tipo de droga até o ano de 2013. Destes, a cada três usuários, uma é do sexo feminino. Estes dados são alarmantes e ao mesmo tempo preocupantes pois a grande maioria destas mulheres encontra-se em período fértil. Mesmo tendo estes altos índices de mulheres que fizeram uso de drogas, não existem dados fidedignos e estatísticos mundiais no que se refere as gestantes usuárias de drogas e os resultados finais perinatais (ANTUNES, et al. 2018).

Apesar de que o sexo masculino (três vezes mais), apresenta maior propensão nas questões relacionadas ao uso de drogas, comparado com as mulheres, esta situação está se tornando cada vez mais preocupante, pois cada vez mais, os profissionais de saúde estão identificando mulheres gestantes usuárias de drogas, incluindo o crack. O contato com a droga durante a gestação pode afetar a integridade não somente da mãe, mas também do feto (UNODC, 2015). Estes dados assemelham-se aos discursos do sujeito coletivo desta pesquisa, quando os profissionais enfermeiros identificam, o aumento de mulheres gestantes usuárias de crack e também despertam a preocupação com o futuro do bebê.

O fato de ser mulher gestante, somado as questões relacionadas ao uso de crack durante a gestação, provoca problemas e complicações para o binômio mãe-filho, pelo fato da rapidez e do alto poder de absorção dessa substância psicoativa. Essa chega até a corrente sanguínea logo após ser consumida, tendo um efeito breve, de curta duração, levando essas pessoas a dependência. Por estas razões as gestantes usuárias de crack são consideradas de alto risco, gerando preocupação por parte da equipe de saúde. Elas podem ter maior chance de intercorrências, precisando de uma assistência integral, mais efetiva e humanizada por parte da equipe que presta cuidados e que estão envolvidas com o tratamento e a reabilitação destas mulheres (WRONSKI et al. 2016). Por estas razões, quase a totalidade das criança, filhas das usuárias de crack, logo após o nascimento vão para a UTI Neonatal, necessitando de 
cuidados mais intensos e muitas vezes os profissionais não levam em consideração o binômio mãe-filho, evidenciando a preocupação com o bebê e não com a saúde desta mulher.

Os enfermeiros, são um elo importante no cuidado à gestante usuária de crack que apresenta alto risco de saúde em função do uso dessa substância psicoativa. Estes profissionais, por estarem a maior parte do tempo junto a estas mulheres conseguem criar um maior vínculo. Exercem a função de assistência direta a esta população vulnerável, dispensando cuidados efetivos, promovendo a saúde destas, prevenindo agravos. Neste contexto evidencia que o profissional enfermeiro tem um grande potencial para identificar problemas relacionados ao uso de drogas e está apto a realizar atividades assistenciais, visando o acolhimento e aproximação destas mulheres para os serviços de saúde (WRONSKI et al 2016).

Corroborando com estas questões, pode-se afirmar que os profissionais são peças chaves no processo de transformação social, pois planejam e desenvolvem programas voltados a prevenção do uso de substâncias psicoativas, também para a reabilitação e reinserção social dos usuários

Os locais onde prestam assistência a saúde juntamente com a rede social exercem um papel de vital importância na assistência aos usuários de drogas, visando um cuidado integral, singular e humanizado a esta clientela, facilitando a interação destes usuários com o serviço, criando e fortalecendo vínculos, a fim de facilitar a adesão e a permanência destes no serviço de saúde. Consequentemente, estes usuários se sentirão mais acolhidos quando necessitarem de atendimento inclusive em momentos mais delicados como por exemplo uma gestação (WRONSKI et al. 2016).

A assistência prestada as mulheres gestantes usuárias de crack, é complexa, exigindo da equipe de saúde um preparo maior para lidar com as adversidades. Esta equipe deve atuar frente a questões complexas como as características psicológicas e sociais destas mulheres, tendo em vista que o uso de crack durante o período gestacional pode alterar aspectos psicológicos, culturais, fisiológicos e sociais relacionados ao viver destas mulheres (CAMARGO et al, 2018). Por vezes os profissionais estão mais centrados na doença física em detrimento da emocional, a preocupação maior dos profissionais de saúde é com esse tipo de clientela, que apresenta algum tipo de doença. 
Toda a mulher que vivencia a experiência da maternidade apresenta diversos sentimentos, anseios, preocupações, insegurança e angústias que podem ser potencializados quando a mulher enfrenta algum tipo de adversidade, como é o caso da gestação e do uso do crack. O uso pode dificultar a adesão destas mulheres ao tratamento, interferindo diretamente na forma como cada mulher irá lidar com a situação vivenciada.

Mulheres gestantes usuárias de crack vivenciam sentimento de insegurança, preocupação e responsabilidade, assim como qualquer outra mulher que não tenha em seu cotidiano a prática do uso de crack. A diferença é que essas, ainda vivenciam o sentimento de culpa, podendo se sentirem desamparadas e constrangidas e acharem que não serão boas mães. A condição de dependentes de drogas psicoativas apresenta uma gravidez permeada por um contexto social geralmente vulnerável. Mulheres usuárias de crack, além destes sentimentos intrínsecos a esta condição podem enfrentar preconceito e estigma social. Por vezes são julgadas como incapazes de exercer o papel de mãe, sendo excluídas socialmente, afastadas da sociedade e da família de modo geral (CAMARGO et al 2018).

Os dados desta pesquisa puderam evidenciar que algumas mulheres usuárias de crack têm sentimentos de proteção com o seu filho e se sentem culpadas por estarem expondo o seu filho ou o feto a substâncias psicoativas em um local que muitas vezes não é apropriado, tendo a consciência dos malefícios principalmente para o seu filho. Este fato pode ser evidenciado pelos profissionais nesta pesquisa, onde muitas vezes esse relato é bem presente no discurso destas mulheres, ficando evidente que elas precisam de ajuda para enfrentar esta situação.

A vergonha e o medo são sentimentos frequentes entre os usuários de drogas. Estudo acerca das estratégias de enfrentamento do craving em dependentes de crack em tratamento em Comunidades Terapêuticas as participantes relataram que são discriminadas e estigmatizadas socialmente, excluídas, tendo que viver a margem da sociedade. (CALHEIROS et al, 2019).

Mulheres gestantes usuárias de crack, conseguem reconhecer os malefícios que o consumo de crack durante a gestação pode causar aos filhos. Por outro lado, o sentimento de culpa e o desejo de afastar-se de vez do mundo das drogas, também é real e um grande problema enfrentado por estas mulheres. Elas visam a redução do consumo da substancia 
psicoativa, buscando minimizar os danos causados pela droga a seus filhos, sendo que manter-se abstinente por completo para algumas dessas mulheres não é possível (CAMARGO et al, 2018). Ancoradas em diversos relatos e vivências no cuidado a essas mulheres na Maternidade e Centro Obstétrico enfermeiras e equipe no geral, acabam prejulgando e estigmatizando-as, ao invés de aproximarem essas mulheres usuárias de crack do serviço de forma acolhedora.

As mulheres são vistas socialmente como responsáveis pela família, sendo consideradas as principais cuidadoras. Quando estas fazem o uso de drogas, deixam de ser respeitadas e, consequentemente, são vistas como promiscuas, irresponsáveis e as únicas responsáveis pela sua condição de usuárias de substância psicoativas (MEDEIROS et al, 2015). Para estas mulheres que se encontram na condição de drogadição, o apoio social é de fundamental importância, não somente a mulher usuária de drogas, mas todos os sujeitos que se encontram nesta mesma situação. A fim de que consigam quebrar o estigma sofrido, que os deixa em situação de marginalização o que estas pessoas precisam é de apoio, de confiança, para conseguir (re)construir as relações socio-afetivas, até mesmo para enfrentar o uso da substância.

Mulheres usuárias de substância psicoativa, em especial as consumidoras de crack que se encontram na condição de gestantes ou parturientes, são diariamente desrespeitadas, estigmatizadas, e percebidas socialmente, inclusive pela equipe de saúde como pessoas sem moral, incapazes de cuidar delas mesmas, consequentemente não são capazes de cuidar de seus filhos (MEDEIROS et al, 2015). Na maioria das vezes, o foco social geralmente é a substância e raras as vezes as mulheres usuárias de crack, a sua história de vida e o seu contexto socio-eco-cultural (CAMARGO et al 2018).

Compreende-se que os determinantes culturais e sociais exercem grande influência neste processo, sendo que o ambiente sócio cultural em que estas mulheres estão inseridas, exerce interferências nas experiencias e relações vivenciadas por elas. A cultura perpassa por todas as interrelações e interconexões. Por esta razão deve ser sempre levada em conta, ficando evidente a importância de tirar o olhar que recai sobre a substância e pensar mais na história de vida desta mulher, no contexto em que ela está inserida, tentando minimizar o estigma e o preconceito por elas vivido, que, por vezes, impedem que sejam ouvidas e respeitadas pela sociedade (CAMARGO et al 2018). 


\section{CONSIDERAÇÕES FINAIS}

O estudo objetivou conhecer as representações sociais de enfermeiras que atuam em Maternidade e Centro Obstétrico acerca da assistência de enfermagem prestada à mulher grávida usuária de crack nos setores. As representações sociais da equipe são de que essas são recebidas da mesma forma que as que não fazem o uso do crack, mas a preocupação por parte da equipe é com o bebê que irá nascer.

O fluxo de atendimento delas no hospital consiste em fazer uma ficha de atendimento no Pronto Socorro, encaminhá-las ao Centro Obstétrico e caso necessitem ou após o parto ficam internadas na Maternidade. Apesar dessa percepção, essas mulheres ao serem recebidas no setor sofrem algum tipo de discriminação por parte de alguns profissionais. Esses fazem julgamentos, indiretas, comentários, críticas, deboche, deixam as mulheres sozinhas, não conversam com elas e manifestam preconceito. Acreditam que a forma como estas mulheres são recebidas no setor depende das crenças, valores e concepções de vida de cada profissional. As profissionais que prestam assistência às mulheres usuárias de crack são acolhedoras durante o cuidado.

Os dados possibilitaram concluir que o cuidado à mulher gestante usuária de crack na Maternidade e Centro Obstétrico é complexo, exige capacitação da equipe de enfermagem para dar conta da necessidade de assistência. Verifica-se que as políticas públicas especificas para o atendimento de pessoas usuárias de drogas não dão conta da especificidade da mulher dependente química, principalmente da gestante.

É necessária a capacitação dos enfermeiros que atuam na assistência a estas mulheres, a fim de minimizar as dificuldades que possuem em prestar-lhes assistência. É preciso combater a falta de respeito, o preconceito, a desumanização, o julgamento, a falta de ética e de paciência, a resistência e as dificuldades pessoais no atendimento a estas mulheres. É preciso combater também o estigma que envolve a temática do uso de crack e do ser mulher gestante. Os serviços especializados no atendimento a pessoa usuária de drogas precisam se adequar para dar suporte à mulher gestante usuária de crack e sua família, constituindo-se como parte de sua rede de apoio social. 


\section{Ventura et al.}

\section{REFERÊNCIAS}

ANTUNES, M. B et al.. Desfecho perinatal em gestantes usuárias de drogas atendidas em um centro especializado. SMAD Revista ElectronicaSalud Mental, Alcohol y Drogas, v. 14, n. 4. 2018.

BRASIL. CONSELHO NACIONAL DE SAÚDE. Resolução 466, de 11 e 12 de dezembro de 2012. Dispõe sobre diretrizes e normas regulamentadoras de pesquisa envolvendo seres humanos, Brasilia-DF.2012.

BOSKA, G. A., et al. Vulnerabilidade para o comportamento sexual de risco em usuários de álcool e outras drogas. SMAD Revista Eletrônica Saúde Mental Álcool e Drogas (Edição em Português), v. 13, n. 4, p. 189-195, 2017.

CALHEIROS, P.R. V., et al. Estratégias de enfrentamento do craving em dependentes de crack em tratamento em Comunidades Terapêuticas. SMAD. Revista eletrônica saúde mental álcool e drogas, v. 15, n. 2, p. 12-19. 2019.

CAMARGO, P.O. et al.. O enfrentamento do estigma vivido por mulheres/mães usuárias de crack. SMAD. Revista eletrônica saúde mental álcool e drogas, v. 14, n. 4, p. 196-202. 2018.

LEFEVRE, F.; LEFEVRE, A. M. C. Pesquisa de Representação Social. Um enfoque qualiquantitativo. Brasilia (DF): Liberlivro. 2012.

MEDEIROS, K. T. et al..Vivências e Representações sobre o Crack: Um Estudo com Mulheres Usuárias. Psico-USF, Bragança Paulista, v. 20, n. 3, p. 517-528. 2015.

MINAYO, M.C.S. o desafio do conhecimento: pesquisa qualitativa em saúde. 14ª ed. São Paulo: Hucitec, 2014.

MACIEL, L. et al. Percepções de Profissionais sobre Atendimentos em Saúde para Mulheres Usuárias de Crack. Psicologia: Ciência e Profissão, v. 40, 2020.

OLIVEIRA, R. O Assistente Social e os processos de criminalização e patologização da população em situação de rua. Sociedade em Debate, v. 26, n. 1, p. 122-134, 2020.

SILVA, É. B. O; PEREIRA, A. L. F; PENNA, L. H. G. Estereótipos de gênero no cuidado psicossocial das usuárias de cocaína e crack. Cadernos de Saúde Pública, v. 34, p. e00110317, 2018.

UNODC. United Nations Office on Drugsand Crime. World drugreport 2015. New York, United Nations. https://www.unodc.org/lpo-brazil/pt/frontpage/2015/06/relatorio-mundial-sobre-drogas-de-2015--o-uso-de-drogas-eestavel--mas-o-acesso-ao-tratamento-da-dependencia-e-do-hiv-ainda-e-baixo.html

VENTURA, J. et al. Representações sociais de enfermeiras acerca do cuidado que mulheres usuárias de crack prestam ao recém-nascido. Revista de Psicologia, v.11 n2, p. 81-89. 2020.

XAVIER, D. M.; et al.. Puérperas usuárias de crack: dificuldades e facilidades enfrentadas no cuidado ao recém-nascido. Aquichan, v. 18, n. 1, p. 32-42. 2018.

WRONSKI, J. L., et al.. Uso do crack na gestação: vivências de mulheres usuárias. Rev enferm UFPE on line., Recife, v. 10, n. 4, p. 1231-9. 2016.

\section{(c) $\mathrm{Br}$}

Este trabalho está licenciado com uma Licença Creative Commons - Atribuição 4.0 Internacional. 